\title{
Knowledge, Attitudes and Practices of Health Care Staff about Glaucoma in Lomé
}

\author{
Messan Kokou Amedome ${ }^{*}$, Yao Ako Patrick Mensah², Kokou Vonor ${ }^{3}$, Nidain Maneh4, \\ Kossi Dzidzinyo ${ }^{5}$, Kassoula Batomaguéla Nonon Saa ${ }^{5}$, Koffi Didier Ayena ${ }^{2}$, Komi Balo ${ }^{5}$ \\ ${ }^{1}$ Centre Hospitalier Universitaire de Kara, Kara, Togo \\ ${ }^{2}$ Hôpital de Bè Lomé, Lomé, Togo \\ ${ }^{3}$ Centre Hospitalier Régional de Kara-Tomdè, Kara, Togo \\ ${ }^{4}$ Centre Hospitalier Universitaire Campus de Lomé, Lomé, Togo \\ ${ }^{5}$ Centre Hospitalier Universitaire Sylvanus Olympio de Lomé, Lomé, Togo \\ Email: *amedomekokoumessan@gmail.com
}

How to cite this paper: Amedome, M.K., Mensah, Y.A.P., Vonor, K., Maneh, N., Dzidzinyo, K., Saa, K.B.N., Ayena, K.D. and Balo, K. (2021) Knowledge, Attitudes and Practices of Health Care Staff about Glaucoma in Lomé. Open Journal of Ophthalmology, 11, 163-175.

https://doi.org/10.4236/ojoph.2021.112013

Received: January 27, 2021

Accepted: May 28, 2021

Published: May 31, 2021

Copyright (c) 2021 by author(s) and Scientific Research Publishing Inc. This work is licensed under the Creative Commons Attribution International License (CC BY 4.0).

http://creativecommons.org/licenses/by/4.0/

\begin{abstract}
Introduction: Glaucoma is a major cause of irreversible blindness worldwide. Early detection and awareness are essential to reduce the impact on eye health. The aim of this study is to assess the knowledge, attitudes and practices of health care staff about glaucoma in Lomé. Materials and Methods: This was a prospective cross-sectional and descriptive study including health care staff in Lomé, from October 1st to December 31st, 2020, for a period of 3 months. After their agreement, the officers responded to questions based on a survey sheet. Results: A total of 169 agents from 3 centers in Lomé, i.e. the Sylvanus Olympio University Teaching Hospital, the Campus University teaching Hospital and the Bè Hospital were involved. 50.9\% of the agents were male versus $49.1 \%$ female, i.e. a ratio of 1.04 . The average age was $33.66 \pm 10.45$ years. $46.10 \%$ were doctors versus $53.90 \%$ paramedics. $58.60 \%$ had at most 5 years of experience against $41.40 \%$ who had more than 5 years of experience. $53.80 \%$ defined glaucoma as ocular hypertension while $17.20 \%$ defined it as optic nerve disease. $46.20 \%$ did not know that there were many types of glaucomas compared to $53.20 \%$ who knew that there are many types of glaucomas. $92.30 \%$ knew that glaucoma can lead to cause visual loss. Regarding attitudes and practices about glaucoma, 91.70\% declared that the follow-up should be done by the ophthalmologist, $81.10 \%$ thought that it would be necessary to be checked by the doctor only every 6 months. Finally, $65.08 \%$ declared that they had to use eye drops for life for the treatment. Conclusion: Steps should be taken to educate staff more about glaucoma attitudes and practices and also plan for action in the population.
\end{abstract}




\section{Keywords}

Knowledge, Attitude, Practice, Glaucoma, Lomé

\section{Introduction}

Glaucoma is defined as an optic neuropathy with structural damage (optic disc) and functional (loss of visual field) loss [1] [2]. Three major types of glaucoma are observed namely the open-angle glaucoma, the narrow-angle glaucoma and the congenital glaucoma. Each of the first two types can give rise to primary or secondary glaucoma, the latter being secondary to ophthalmic or systemic pathology affecting the optic nerve.

Glaucomas are the second leading cause of blindness in the world after cataracts [3]. They are the leading cause of irreversible blindness and represent about $15 \%$ of all causes of blindness [4]. Of the 45 million blind people in the world, nearly 6 million are believed to be carriers of glaucoma, or 15\% of the causes of blindness. According to a meta-analysis by Quigley, the number of glaucomatous patients is estimated at 66 million worldwide.

In Africa, their number is estimated to be $7,026,000$. The severity of the disease is explained by the low rate of diagnosis in developed countries, $50 \%$ of cases of glaucoma are not diagnosed, probably at least $75 \%$ in less developed countries [5]. All these aspects require, as far as possible, early referral, screening and management for practitioners.

Previous studies published on glaucoma in Togo in the urban population have shown that patients are not aware of the disease [6]. Other similar studies have been carried out in hospitals outside our borders showing a low level of knowledge of glaucoma by healthcare workers [7] [8].

Among non-ophthalmologist nursing staff, it is clear that there is a wide range of knowledge about glaucoma. However, none have yet been made among the nursing staff in Lomé. It is with a view to improving prevention and diagnostic strategies, assessing the level of knowledge of the caregiver in case of glaucoma that we conducted this study, the aim of which is to assess the knowledge, practices and attitudes of practitioners about glaucoma.

\section{Material and Methods}

We carried out a multicenter study including 3 hospitals in Lomé, namely the Sylvanus Olympio University Teaching Hospital (Centre Hospitalier Universitaire Sylvanus Olympio), the Campus University Teaching Hospital (Centre Hospitalier Universitaire Campus) and the Hospital of Bè (Hôpital de Bè) in Lomé. It was a prospective cross-sectional study with a descriptive aim which took place over a period of 3 months between October and December 2020. This study included non-ophthalmological health practitioners regardless of the position held. After the validity and the reliability of questionnaire from a small group 
of practitioners, a total of 250 survey forms which was the questionnaire of 42 questions were sent after survey and consent to agents of 3 departments namely the medicine, surgery, gyneco-ostetrics and pediatrics departments of the 3 health centers. Finally, 169 forms were completed and collected. To define a good knowledge of glaucoma we considered questions in relation with the knowledge of glaucoma which corresponded on the questionnaire all the questions from number 17 to number 36 i.e. 20 questions. We defined the score of knowledge bad if only 0 - 9 questions are correctly answered, medium if 10 - 14 are correctly answered and good if 15 - 20 questions are correctly answered. Three parameters were evaluated namely knowledge about glaucoma, attitudes about and practice about glaucoma. Data were entered and processed using Epidata software version 3.1.

The main difficulty encountered in this study is the unavailability of certain healthcare practitioners because of the pandemic of coronavirus disease.

\section{Results}

\subsection{Socio-Demographic Characteristics of the Sample}

A total of 196 agents out of 250 contacted responded to the questionnaire, i.e. a participation rate of $67.6 \%$. Compared to the center, there were 72 respondents for Sylvanus Olympio University Teaching Hospital, 42 for Campus University Teaching Hospital and 55 for Bè Hospital, i.e. respectively 42.60\%, 24.90\% and $32.50 \%$. Regarding the distribution by sex, there were 86 men and 83 women which represented respectively $50.90 \%$ and $49.10 \%$, or a sex ratio of 1.04 . The average age was $33.66 \pm 10.45$ years. The distribution of respondents according to age group is summarized in Figure 1. Regarding the qualification of agents, $46.10 \%$ were doctors and $53.90 \%$ paramedical practitioners. The distribution of the subjects surveyed in relation to their qualification is summarized in Figure 2. Regarding seniority in the profession, $58.60 \%$ had at most 5 years of experience



Figure 1. Distribution of respondents according to age groups. 


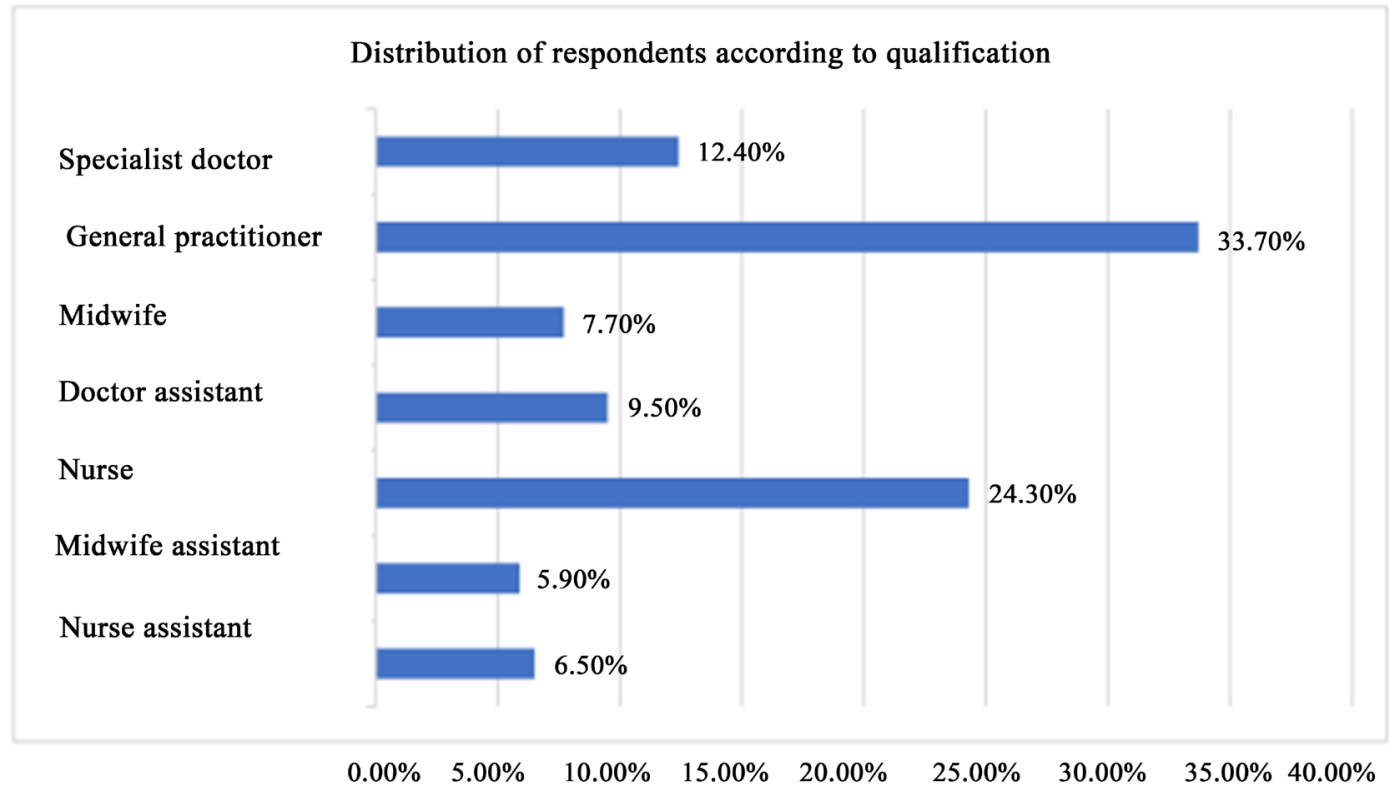

Figure 2. Distribution of respondents according to qualification.

against $41.40 \%$ who had more than 5 years of experience.

\subsection{General Knowledge and Awareness about Glaucoma}

- About the definition of glaucoma, $21.30 \%$ of the practitioners defined glaucoma as an eye disease while $53.80 \%$ defined it as a high intraocular pressure and $17.20 \%$ as an optic nerve disease. At the end, 3.60\% defined it as an inflammation or infection of eye and $4.10 \%$ didn't know any definition of glaucoma.

- With regard to glaucoma awareness, $98.20 \%$ said they had been sensitized about glaucoma versus $1.80 \%$ who had never been sensitized about glaucoma.

- About the question if they did know the different types of glaucoma, $39.10 \%$ cited primary open angle glaucoma, $37.90 \%$ cited the angle closure glaucoma, $7.70 \%$ cited congenital glaucoma (Table 1).

- Questions about who glaucoma affect, its risk factors, its clinical signs and prognostic and questions about congenital glaucoma also were concerned by the questionnaire. Practitioners' opinions are summarized in Table 2. Compared to the level of overall knowledge about glaucoma according to our study, $51.5 \%$ have good knowledge while $48.5 \%$ have poor knowledge of glaucomatous disease.

\subsection{Attitudes and Practices on Glaucoma}

- When asked what to do in case of glaucoma, $60.90 \%$ answered that they must consult a doctor and $39.10 \%$ said they must scrupulously respect the follow-up appointments for the treatment. None of them mentioned that the must pray, or refer to traditional medical practitioner or abandon their glaucoma treatment. Concerning attitudes more precisely the treatment in case of 
Table 1. Types of glaucomas.

\begin{tabular}{ccc}
\hline Types of glaucomas & $\mathrm{Nb}$ & $\%$ \\
\hline Congenital glaucoma & 13 & $7.70 \%$ \\
Adult glaucoma & 9 & $5.30 \%$ \\
POAG & 66 & $39.10 \%$ \\
Angle closure glaucoma & 64 & $37.90 \%$ \\
Normal tension glaucoma & 3 & $1.80 \%$ \\
Secondary glaucoma & 1 & $0.60 \%$ \\
Chronic glaucoma & 1 & $0.60 \%$ \\
Ischemic glaucoma & 1 & $0.60 \%$ \\
Total & 169 & \\
\hline
\end{tabular}

Table 2. Concepts on glaucoma.

\begin{tabular}{|c|c|c|c|}
\hline Concepts on glaucoma & Yes & No & Don't know \\
\hline It affects only adults & 16 & 121 & 32 \\
\hline Glaucoma leads to vision loss & 156 & 4 & 9 \\
\hline Probability high with HBP and diabetes & 95 & 23 & 51 \\
\hline $\begin{array}{l}\text { Observing the sun directly without a sunglasses } \\
\text { can lead to glaucoma }\end{array}$ & 15 & 86 & 68 \\
\hline Glaucoma is manifested by eye scratching and eyelid swelling & 21 & 101 & 47 \\
\hline $\begin{array}{l}\text { Eye pain, gradual loss of visual acuity and } \\
\text { tearing suggests chronic glaucoma }\end{array}$ & 95 & 22 & 52 \\
\hline Glaucoma-related blindness is curable & 34 & 99 & 36 \\
\hline Probability of having glaucoma increases with age & 101 & 25 & 43 \\
\hline Black people are more likely to have glaucoma than white & 39 & 13 & 117 \\
\hline $\begin{array}{l}\text { Triad "Big beautiful eyes, photophobia and tearing" in } \\
\text { newborns is reminiscent of congenital glaucoma }\end{array}$ & 77 & 17 & 74 \\
\hline
\end{tabular}

Table 3. Attitudes and practices about glaucoma.

Glaucoma can be treated with surgery

Glaucoma is treated by instillation of eye drops for life

Glaucoma is also treated par LASER

In case of congenital glaucoma wait until 5 years

In case of congenital glaucoma parents must be reassured that it will be okay when he grows up

In case of congenital glaucoma, refer to ophthalmologist

$\begin{array}{lll}80 & 55 & 34 \\ 110 & 22 & 37 \\ 56 & 16 & 96 \\ 15 & 70 & 83 \\ 26 & 78 & 64 \\ 80 & 38 & 51\end{array}$

glaucoma, the practitioners said that a medical treatment, surgical treatment and physical treatment exist (Table 3). About the frequency of appointments during the following up, some practitionners thought about one appointment every 6 months, those said only one checking up a year and the last group 
said occasional appointment.

- Finally some correlations had been established among people in different level of scolarisation and knowledge about glaucoma firstly and secondly among people in different qualification and knowledge about glaucoma. It appears that the correlation between knowledge of glaucoma and school level is significant with a chi-square test $=4.702 ; \mathrm{p}=0.03(\mathrm{p}<0.05)$ but the correlation between knowledge of congenital glaucoma and school level is not significant $\left(\mathrm{chi}^{2}\right.$ test $=1.27 ; \mathrm{p}=0.25$ ( $\left.\mathrm{p}>0.05\right)$; the correlation between the school level and the level of awareness is significant $(\mathrm{p}<0.05)$ and the correlation between knowledge of congenital glaucoma and the service of practitioner is not significant $\left(\mathrm{chi}^{2}=3.40\right.$ with a $\left.\mathrm{p}>0.05\right)$.

\section{Discussion}

\subsection{Socio-Demographic Characteristics of the Population and Type of Study}

The multicentric character of our study is comparable to that carried out by Monsudi et al. in Nigeria [9], Ichhpujani et al. in India [10] and Khawaja et al. [11] in Pakistan with the targeting of health care practitioner. Compared to the socio-demographic nature of our sample, we had a young population with an average age of $33.66 \pm 10.45$ years. These results are similar to those of Monsudi et al. [9], Khawaja et al. [11] who in their studies found an average age of 36 years and 32.42 years respectively. This similarity could be explained by the age pyramid. It corresponds in fact to the most active and important average age on the labor market in our developing countries. We noted a slight male predominance in our study with a sex ratio of $1.04(86 \mathrm{H} / 83 \mathrm{~F})$. Similar results were found by Monsudi et al. [9] in Nigeria and Khawaja et al. in Pakistan [11] with a sex ratio of 1.3 and 1.7, respectively. On the other hand, a female predominance was found by Ichhpujani et al. [10] in India with a sex ratio of 0.4.

According to the data in the medical literature, there would be a male predominance among the nursing staff [12], which thus corroborates with our results.

\subsection{Knowledge and Awareness of Glaucoma}

\subsubsection{Awareness of Glaucoma}

In our study $98.2 \%$ had once heard of glaucoma while Komolafe et al. had reported $100 \%$ [13] in Nigeria, Ichhpujani et al. [10] in India in their work. A lower proportion of $76.1 \%$ and $63.3 \%$ respectively were found by Monsudi et al. [9] and Osaguona et al. in Nigeria [14]. In general, the level of awareness remains high compared to the various studies in several developing countries leaded by Balo [6]; Ogbonnaya et al. [15] who found 29\% and $21.1 \%$ respectively. The high level of awareness among clinical staff in these studies is not surprising, as they are expected to have had glaucoma lectures during their training.

The majority of information on glaucoma was collected during their training among $70.7 \%$ of the practititoners. The same conclusion was made by Osaguona 
et al. [14] Ichhpujani et al. [10], Onabolu et al. [16] in their different studies. On the other hand, Monsudi et al. [9] noted that the hospital seminars were the most important source of information which is quite understandable given the quarterly postgraduate presentations made by ophthalmology department in this hospital. The low proportion of the mass media could be explained by the lack of programs produced by health professionals to raise public awareness.

Awareness through friendships in our study was low like that of Askira et al. [17], Monsudi et al. [9]; this may be due to reluctance to disclose a health problem among friends or that eye health staff do not inform patients about their situation.

\subsubsection{Knowledge about Chronic Glaucoma}

In our study, more than half of the practitioners, i.e. $51.5 \%$, had a good level of knowledge about chronic glaucoma. These results are in the same direction as those found by Osaguona et al. [14], Khawaja et al. [11] who found respectively $62.5 \%$ and $91 \%$ of good level of knowledge about glaucoma. On the other hand, our results are contrary to those found by Onabolu et al. [16] who found in their study that less than half of their sample, i.e. $42.5 \%$, had a good level of knowledge about glaucoma. In addition, we noted a very significant correlation between the level of knowledge and the level of education on the one hand and between the level of knowledge and the qualification on the other hand, as in certain studies of the literature [6] [11] [18]. In terms of heredity and age factors, participants knew that heredity (69.2\% of the sample) and age (59.7\%) are important risk factors for glaucoma. However, other authors have reported eye trauma and intraocular infection as the major risk factors for glaucoma according to their studies [9]. Of the consequences on the optic nerve, $17.2 \%$ said glaucoma is a disease that damages the optic nerve due to increased pressure in the eye. Some authors found a higher result of $27.5 \%$ [10], while others reported $39.2 \%$ in their study. Most of the participants, $92.3 \%$, said that untreated glaucoma could lead to blindness. This strong finding has also been made but to a lesser extent in other studies [9] [16]. About the different types of glaucoma treatment, according to our results, $33.7 \%$ of participants were aware of laser treatment. This finding has been noted but to a lesser extent by other authors in their work [9].

\subsection{Knowledge of Congenital Glaucoma}

With regard to congenital glaucoma, a smaller proportion, i.e. $22.5 \%$ of practitioners, were aware of this type of glaucoma, a type of glaucoma, moreover, quite rarer according to data in the literature.

Photophobia, tearing and large eyes were recognized by $46.2 \%$ as signs of congenital glaucoma. These results are similar to those found by Marco et al. [19] Michel et al. in Brazil [20]. In all cases, awareness of the symptoms of congenital glaucoma compared to glaucoma in adults remains low and this could be attributed to the relative rarity of this pathology. 


\subsection{Attitude and Practice about Glaucoma}

According to our study, when diagnosed with glaucoma, $60.90 \%$ responded that they needed to see a doctor. This figure is even increased to $91.7 \%$ of the population who would seek help from an ophthalmologist in the event of complications. Balo [6] on the other hand in a previous study found that only $43.9 \%$ will have recourse to an ophthalmologist. This opposition of attitudes is linked to the difference in the level of education on the one hand and on the other hand, the study by Balo et al. [6] being carried out in the semi-urban population and ours among the nursing staff. Regarding the respect of appointments, $39.1 \%$ of the population had reported the scrupulous respect of appointments for follow-up treatment. This good attitude would probably be linked to the knowledge of certain basics by the nursing staff with regard to the follow-up of the treatment. On the practice regarding glaucoma for follow-up, participants $81.1 \%$ of the staff saw fit to follow up once every 6 months. The gradual application of good practices by healthcare staff would explain these results.

\section{Limitation of the Study}

In the selection procedure, we were unable to interview the nursing staff to see whether or not the agents had to resort to their specialist colleagues to complete the forms, which would be a methodological bias. In addition, it was not possible to identify among the staff those already followed in ophthalmology for glaucoma who would probably be better informed about the disease than their other colleagues. In any case, other studies will be carried out to eliminate these biases with a view to new results.

\section{Conclusions}

In our study the level of awareness is generally good about glaucoma. Most of the information on glaucoma was collected during their training; however the level of knowledge is low especially with regard to congenital glaucoma. There was a significant correlation between knowledge about glaucoma and level of education. The lower the level of study, the less knowledge is good.

This study reveals the need to program awareness campaigns targeting health personnel and then the population by making greater use of the mass media in order to step up the fight against glaucoma. A study subsequent to the previous actions will make it possible to see the level of practical knowledge and skills of the community regarding glaucoma and it would be a great asset in the fight against glaucoma.

\section{Conflicts of Interest}

The authors declare no conflicts of interest regarding the publication of this paper.

\section{References}

[1] Quigley, H.A. and Broman, A.T. (2006) The Number of People with Glaucoma 
Worldwide in 2010 and 2020. British Journal of Ophthalmology, 90, 262-267. https://doi.org/10.1136/bjo.2005.081224

[2] Foster, P.J., Buhrmann, R., Quigley, H.A. and Johnson, G.J. (2002) The Definition and Classification of Glaucoma in Prevalence Surveys. British Journal of Ophthalmology, 86, 238-342. https://doi.org/10.1136/bjo.86.2.238

[3] Bron, A. and Francoz, A. (2014) Le GPAO dans le monde. In: Renard, J.-P. and Sellem, E., Eds., Rapport de la SFO, Elsevier Masson, Paris, 13-21.

[4] Resnikoff, S., Pascolini, D., Etya'ale, D., et al. (2004) Global Data on Visual Impairment in the Year 2002. Bulletin of the World Health Organization, 89, 1559-1564.

[5] Quigley, H.A. and Vitale, S.S. (1997) Model of Open Angle Glaucoma Prevalence and Incidence in the United States. Investigative Ophthalmology \& Visual Science, 38, 83-91.

[6] Balo, P.K., Serouis, G.A., Banla, M., Agla, K., Djagnikpo, P.A. and Koffi-Gué, K.B. (2004) Connaissances, attitudes et pratiques relatives au glaucome dans la population urbaine et semi-urbaine de Lomé. Cahiers détudes et de recherches francophones/ santé, 14, 187-191.

[7] Tenkir, A., Solomon, B. and Deribew, A. (2010) Glaucoma Awareness among People Attending Ophthalmic Outreach Services in Southwestern Ethiopia. BMC Ophthalmol, 10, Article No. 17. https://doi.org/10.1186/1471-2415-10-17

[8] Saw, S.M., Gazzard, G., Friedman, D., Foster, P.J., Devereux, J.G., Wong, M.L. and Seah, S. (2003) Awareness of Glaucoma, and Health Beliefs of Patients Suffering Primary Acute Angle Closure. British Journal of Ophthalmology, 87, 446-449. https://doi.org/10.1136/bjo.87.4.446

[9] Monsudi, K.F., Saka, E.S. and Ayodapo, A.O. (2018) Health Workers Awareness and Knowledge of Glaucoma in Tertiary Hospital in Birnin Kebbi, Nigeria. Ophthalmology Research: An International Journal , 8, 1-8, https://doi.org/10.9734/OR/2018/39379

[10] Ichhpujani, P., Bhartiya, S., Kataria, M. and Topiwala, P. (2012) Knowledge, Attitudes and Self-Care Practices Associated with Glaucoma among Hospital Personnel in a Tertiary Care Center in North India. Journal of Current Glaucoma Practice, 6, 108-112. https://doi.org/10.5005/jp-journals-10008-1116

[11] Khawaja, A.H.S.H, Hashim, I. and Haider, A. (2017) Awareness and Knowledge about Cataract and Glaucoma among Non-Ophthalmology Healthcare Professionals Working in Different Cadres at Two Tertiary Care Hospitals in Mirpur, Azad Kashmir. Journal of University Medical \& Dental College, 8, 56-62.

[12] Eriki, P., Oyo-Ita, A., Odedo, R., Udoh, A., Omaswa, F. and Kadama, P. (2015) Surgical Workforce in Nigeria: Stock and Flow of Medical and Dental Practitionners in Nigeria, with Special Focus on Health Workforce Training in Cross River State. https://www.who.int/workforcealliance/031616NigeriaCaseStudyweb.pdf

[13] Komolafe, O.O., Omolase, C.O., Bekibele, C.O., Ogunleye, O.A., Komolafe, O.A. and Omotayo, F.O. (2013) Awareness and Knowledge of Glaucoma among Workers in a Nigerian Tertiary Health Care Institution. Middle East African Journal of Ophthalmology, 20, 163-167. https://doi.org/10.4103/0974-9233.110609

[14] Osaguona, V.B. and Edema, O.T. (2014) Awareness and Knowledge of Glaucoma among Hospital Workers at the University of Benin Teaching Hospital, Benin City. Sahel Medical Journal, 17, 132-135. https://doi.org/10.4103/1118-8561.146816

[15] Ogbonnaya, C.E., Ogbonnaya, L.U., Okoye, O. and Kizor-Akaraiwe, N. (2016) Glaucoma Awareness and Knowledge, and Attitude to Screening, in a Rural Com- 
munity in Ebonyi State, Nigeria. Open Journal of Ophthalmology, 6, 119-127.

https://doi.org/10.4236/ojoph.2016.62017

[16] Onabolu, O.O. and Bodunde, O.T. (2014) Awareness and Knowledge of Glaucoma among Primary Care Givers in a Developing Country. Annals of Tropical Medicine and Public Health, 7, 5-8.

[17] Askira, B.H., Waziri, M.A., Musa, Z.Y., Ribadu, D.Y. and Kyari, F.A. (2015) Glaucoma Awareness among Tertiary Health Care Workers in Maiduguri, Nigeria. Borno Medical Journal, 12, 30-35.

http://www.bornomedicaljournal.com/pdfs/36_BOMJ_Vol12_No1_BOMJvol12issu e1.pdf

[18] Ntim-Amponsah, C.T., Winifred, M.K.A. and Ofusu-Amaah, S. (2004) Awareness and Knowledge of Glaucoma and Other Diseases Associated with Blindness in a Ghanaian Community. Nigerian Journal of Ophthalmology, 12, 50-54.

https://doi.org/10.4314/njo.v12i2.11947

[19] Wanyama, S.P., Marco, S. and Kariuki, M. (2015) Knowledge, Attitude and Practice of Eye Diseases in Children among Paediatricians in Kenya. The Journal of Ophthalmology of Eastern, Central and Southern Africa, 19.

[20] Michel, B., Mary, Z.S. and Italo, M. (2003) What Do Pediatricians Know about Children's Eye Diseases? Arquivos Brasileiros de Oftalmologia, 66, 489-492. 


\section{Questionnaire: Knowledge, Attitudes and Practices of Health Personnel on Glaucoma in} Lomé

\section{General Informations}

$\mathrm{N}^{\circ}$ Center /_ / Date I_I_III_II_I

No Folder: /_l _ l_l I I

Civil status:

Q1 Age: /_I
[1] $18-29$
[2] 30 - 39
[3] 40 - 49
[4] 50 - 59
[5] 60 and more

Q2 Sex: /_/

[1] male,

[2] female

Q3 Marital status: /_I

[1] married,

[2] widower, [3] divorced, [4] single

Q4 Religion: I_/

[1] Christianity,

[2] Islam,

[3] animism, [4] none,

[5] others

Q5 Scolarisation: / _ /

[1] illiterate,

[2] primary

[3] secondary [4] university

Q6 Profession /_I

[1] Nurse assistant, [2] midwife assistant

[3] nurse,

[4] doctor assistant [5] midwife,

[6] general practitioner,

[7] specialist doctor specify

Q7 Hospital: /__

[1] Sylvanus Olympio University teaching hospital

[2] Campus University teaching hospital

[3] Bè Hospital

Q8 Service: /_/

[1] General Medecine

[2] Gynecology-Obstetric

[3] Pediatrics

[4] Surgery

[5] Stomatology -ENT

Q9 Year of seniority in the position /_I
[1] $<1$ year;
[2] 1 - 5 years;
[3] 6 - 10 years;
[4] 10 - 15 years,
[5] 16 years and more (Specify.......years)

\section{Background}

Q10 Do you have a parent with a chronic eye condition? /_/ [1] Yes [2] No [3] Don't know

Q11 If Yes, specify I_I

[1] cataract [2] glaucoma [3] refractive error (myopia/ presbyopia/hypermetropia /...)

[4] others

Q12 Do you suffer from an eye disease? I_I
[1] Yes
[2] No
[3] Don't know

Q13 If Yes, specify I_/

[1] cataract [2] glaucoma

[3] refractive error (myopia/presbyopia/hypermetropia/...)

[4] others 


\section{Knowledge and Awareness about Glaucoma}

\subsection{Awareness}

Q14 Have you ever heard of glaucoma? /_ / [1] Yes [2] No

Q15 If yes, where? /_ / [1] during my training [2] at the hospital [3] in the mass media (tv, radio, internet...)

$$
\text { [4] by friends [5] others }
$$

Q16 Do you know the name glaucoma in your area: /_ / [1] I don't know [2] I know: give it.......

\subsection{Knowledge about Chronic Glaucoma}

Q17 What is glaucoma? /__ /

[1] it is an eye disease [2] it is a high intraocular pressure [3] it is a disease of the nerve in the eye

[4] it is inflammation or infection of the eye

[5] don't know

[6] Other

Q18 Do you know the different types of glaucoma? /__ /
[1] Yes
[2] No

Q19 if yes, name two types

Q20 The probability of having glaucoma is high if a family member has it /_/

[1] Yes [2] No [3] Don't know
Q21 Glaucoma only affects adults over $40 / \ldots$
[1] Yes
[2] No
[3] Don't know

Q22 Glaucoma causes vision loss /_ /
[1] Yes
[2] No
[3] Don't know

Q23 Does the probability of having glaucoma increase with the existence of high blood pressure and/or di-
abetes? /_I
[1] Yes
[2] No
[3] Don't know

Q24 Observing the sun directly without a sunglasses can lead to glaucoma /_ / [1] Yes [2] No [3] Don't know Q25 Glaucoma is manifested by eye scratching and eyelid swelling /_ / _ [1] Yes [2] No [3] Don't know Q26 Eye pain, gradual loss of visual acuity and tearing suggests chronic glaucoma /_ /

$\begin{array}{llll} & {[1] \text { Yes }} & \text { [2] No } & \text { [3] Don't know } \\ \text { Q27 Glaucoma-related blindness is curable /_/ } & \text { [1] Yes } & \text { [2] No } & \text { [3] Don't know }\end{array}$

Q28 The probability of having glaucoma increases with age /_/ [1] Yes [2] No [3] Don't know Q29 Black people are more likely to have glaucoma than white /_/ [1] Yes _ [2] No [3] Don't know Q30 Glaucoma can be treated with surgery /__ / [1] Yes [2] No [3] Don't know Q31 Glaucoma is treated by instillation of eye drops for life /_ / [1] Yes [2] No [3] Don't know Q32 Glaucoma can also be treated with a laser /__ / [1] Yes [2] No [3] Don't know 


\subsection{Knowledge about Congenital Glaucoma}

Q33 Big beautiful eyes, photophobia and tearing in newborns are reminiscent of congenital glaucoma /_/
[1] Yes
[2] No
[3] Don't know

Q34 In case of congenital glaucoma in a newborn baby, you have to wait until the child is 5 years old /_I
[1] Yes
[2] No
[3] Don't know

Q35 In case of congenital glaucoma in a newborn baby, parents must be reassured that it will be okay when he grows up I_I [1] Yes [2] No [3] Don't know

Q36 In case of congenital glaucoma in a newborn baby, he must be referred quickly to an ophthalmologist for surgery / _ / [1] Yes [2] No [3] Don't know

\section{Attitudes in Case of Glaucoma}

Q37 Which health care provider are you followed for screening for eye complications of glaucoma /_/

[1] General practitioner [2] Ophthalmologist [3] Nurse [4] Ophthalmologist assistant [5] others (specify).

Q38 Regular intraocular pressure (IOP) measurement is necessary even in the absence of eye symptoms /_ /
[1] Yes
[2] No
[3] Don't know

Q39 What would you do if you were diagnosed with glaucoma? I_/

[1] consult my attending physician [2] resort to traditional medicine [3] abandon all treatment

[4] pray [5] scrupulously respect my follow-up appointments for my treatment [6] others (specify)

\section{Practice on Glaucoma}

Q40 How often is a check-up necessary for monitoring glaucoma?
[1] once every 6 months
[2] once a year
[3] occasionally
[4] other (specify) / _ /

Q41 What are your motivations for having the fundus exam regularly I_I
[1] Fear of losing their sight
[2] recommendation of the attending physician
[3] availability of financial means or insurance
[4] other (specify)

Q42 What are the barriers to completing the regular IOP exam? I_I
[1] Not informed
[2] does not consider it necessary in the absence of visual disturbances
[3] lack of financial means
[4] others (specify).

Thank You 